\title{
Functionalization of hydrogen-free diamond-like carbon films using open-air dielectric barrier discharge atmospheric plasma treatments
}

\author{
J.L. Endrino a,b,*, J.F. Marco ${ }^{c}$, M. Allen ${ }^{\text {d, P. Poolcharuansin }}{ }^{\mathrm{a}, \mathrm{e}}$, \\ A.R. Phani ${ }^{\mathrm{f}}$, J.M. Albella ${ }^{\mathrm{b}}$, A. Anders ${ }^{\mathrm{a}}$ \\ a Lawrence Berkeley National Laboratory, Berkeley, CA 94720, USA \\ ${ }^{\mathrm{b}}$ Instituto de Materiales de Madrid, C.S.I.C., Cantoblanco, 28049 Madrid, Spain \\ "Instituto de Química-Física "Rocasolano" C.S.I.C., 28006 Madrid, Spain \\ 'SUNY Upstate Medical University, Syracuse, NY 13210, USA \\ ${ }^{\mathrm{e}}$ Mahasarakham University, Mahasarakham 44150, Thailand \\ ${ }^{\mathrm{f}}$ CASTI, CNR-INFM Regional Laboratory, L'Aquila 67100, Italy
}

\section{A R T I C L E I N F O}

\section{Article history:}

Received 29 August 2007

Received in revised form 11 January 2008

Accepted 18 February 2008

Available online 26 February 2008

\section{Keywords:}

Ion implantation and deposition

DLC

XPS

Wettability

Cell viability

\begin{abstract}
A B S T R A C T
A dielectric barrier discharge (DBD) technique has been employed to produce uniform atmospheric plasmas of $\mathrm{He}$ and $\mathrm{N}_{2}$ gas mixtures in open air in order to functionalize the surface of filtered-arc deposited hydrogen-free diamond-like carbon (DLC) films. XPS measurements were carried out on both untreated and $\mathrm{He} / \mathrm{N}_{2}$ DBD plasma-treated DLC surfaces. Chemical states of the $\mathrm{C} 1 \mathrm{~s}$ and $\mathrm{N} 1 \mathrm{~s}$ peaks were collected and used to characterize the surface bonds. Contact angle measurements were also used to record the short- and long-term variations in wettability of treated and untreated DLC. In addition, cell viability tests were performed to determine the influence of various $\mathrm{He} / \mathrm{N}_{2}$ atmospheric plasma treatments on the attachment of osteoblast MC3T3 cells. Current evidence shows the feasibility of atmospheric plasmas in producing long-lasting variations in the surface bonding and surface energy of hydrogen-free DLC and consequently the potential for this technique in the functionalization of DLCcoated devices.
\end{abstract}

(c) 2008 Elsevier B.V. All rights reserved.

\section{Introduction}

In a recent study, it was shown that the nanoscale wettability of a hydrogen-terminated diamond surface was lower than that of regions that had been oxidized using an atomic force microscope tip [1]. The difference in wettability between modified diamond surfaces suggests the application of controlled wettability of modified carbon surfaces in the fields of medicine and biotechnology, which could also be extended to diamond-like carbon (DLC) films.

Diamond-like carbon films are known to be hard, low friction and chemically inert materials. Numerous in vitro and in vivo experiments have indicated that DLC can have both excellent biocompatibility and hemocompatibility [2-5]. In the past, the wettability of DLC coatings has been modified by selective doping

\footnotetext{
* Corresponding author at: Surface Physics and Engineering Department, Instituto Ciencia de Materiales, C.S.I.C., Cantoblanco, 28049 Madrid, Spain. Tel.: +34 913349080; fax: +15104864374.

E-mail address: jlendrino@icmm.csic.es (J.L. Endrino).
}

using both metal and non-metal dopants [6-8]. For instance, both silicon and fluorine can be used to increase the surface energy and reduce the contact angle with water. In one study [6], researchers modified the surface energy of DLC by incorporating oxygen and silicon into the bonding network, thus avoiding the use of harmful fluorine-containing hydrocarbon gases. However, the siliconcontaining DLC coatings had 20 times lower wear resistance than undoped DLC films. In another recent study [9], phosphorus-doped DLC films were deposited by applying hybrid plasma immersion ion implantation and deposition (PIIID) techniques; the good wettability exhibited by P-doped DLC samples leads to an increase in hemocompatibility. However, in this study the mechanical properties of the modified films were not analyzed. In a different study [5], substrates with various substrate roughness were employed to investigate the attachment of human osteoblast cells to amorphous carbon films with different surface textures. This study concluded that cell attachment increased monotonically with surface roughness. However, smooth surfaces are critical in the vast majority of biomedical applications and topological functionalization of the surface cannot be seen as a wide-range solution. 


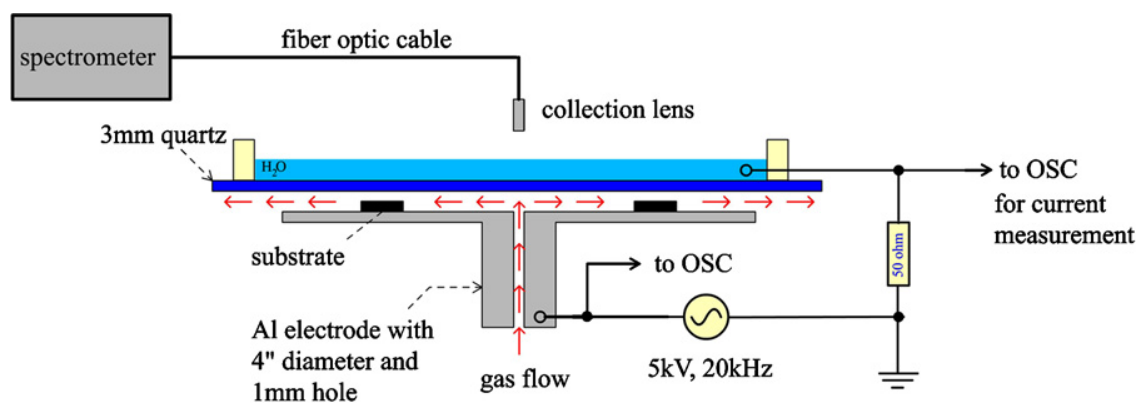

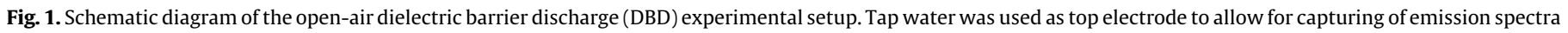
of $\mathrm{He} / \mathrm{N}_{2}$ plasma discharge.

As a result, there is a current need for inexpensive surface processing technologies that can modify the surface energy of DLC without altering the excellent mechanical properties of DLC films. Actually, there is a search for new ways to apply atmospheric plasma discharges that can modify the wettability, surface energy and chemistry of modern materials. In this regard, atmospheric dielectric barrier discharges (DBD) techniques can be used for the cleaning of surfaces as well as for the activation of polymer-like surfaces [10-13]. Polymers are materials of great interests in biomedical fields such as tissue engineering. Therefore, DBD processes are being used to functionalize polymeric materials by inducing changes in the surface energy, and modifying their cellattachment behavior [14]. Stable glow plasmas from reactive gasses such as $\mathrm{N}_{2}$ at atmospheric pressure can be easily obtained by using helium as a carrier gas [15]. Helium has a higher metastable energy level than argon, and this allows for the ionization of the nitrogen molecule, $\mathrm{N}_{2}$, which is known as Penning effect $[16,17]$.

This suggests that DBD could also be useful in modifying the adhesion of cells and proteins to DLC films that are used in diagnostic and medical device applications. In the present study, we have employed open-air $\mathrm{N}_{2} / \mathrm{He}$ DBD plasmas to functionalize the surface of hydrogen-free DLC films. The films were prepared by the filtered cathodic arc which is a well-known technique for the deposition of DLC films with very low-hydrogen content [18-20]. Surface analysis and characterization after functionalization of the surfaces by DBD were performed using X-ray photoelectron spectroscopy and contact angle measurements. We have analyzed the influence of these DBD plasma treatments on the attachment of osteoblast MC3-T3 cells.

\section{Experimental}

Four hydrogen-free DLC films have been deposited using a pulsed filter cathodic arc deposition system that contained a "triggerless" mini-gun incorporating a 6.3-mm diameter graphite rod, which was used as cathode [21]. The pulsed operation of the cathode was controlled using custom National Instruments' LabView $^{\mathrm{TM}}$ software. Once the computer has sent a signal to the arc power supply, pulsed arc discharges on the cathode was triggered simply by application of a high open-circuit voltage, typically $600 \mathrm{~V}$, fed by a pulse-forming network [18]. The plasma stream produced by the source was injected into a $90^{\circ}$ filter to remove most of the macroparticles, which were formed during the cathodic arc process. In the system, the substrates were negatively biased with $2 \mu \mathrm{s}, 1 \mathrm{kV}$ pulses with a pulse duty cycle of $12.5 \%$. The deposited DLC films had an approximate thickness of $45 \mathrm{~nm}$.

The in-house open-air DBD plasma system employed to functionalize the deposited DLC films is shown in Fig. 1. The discharge was generated by a 5-kV AC power supply, which run at a frequency of $25 \mathrm{kHz}$. The base electrode of the plasma source was a flat aluminum disk of $4 \mathrm{in} .(\sim 100 \mathrm{~mm})$ in diameter, which contained a center hole ( $1 \mathrm{~mm}$ in diameter). The aluminum electrode was connected to the high-voltage output of the AC power supply. High purity helium (99.995\%) and nitrogen (99.99\%) were mixed and injected through the center hole, and allowed to expand throughout the discharge gap. The dielectric barrier was a 3.0-mm thick quartz plate, with dielectric constant of 3.07. In our design, water was used as a top transparent electrode, which allowed us to adequately capture the emission spectra of the various surface treatments through an optical fiber connected to an UV-vis spectrometer. In addition, a $50-\Omega$ resistor was placed between the top (water) electrode and the ground, which allowed us to record the current waveforms using a digital oscilloscope (Tektronix TDS 210). To ensure stable plasma operation, the gap width was limited to $1 \mathrm{~mm}$. The list of the various surface treatments applied is shown in Table 1; all three plasma treatments had a duration of $30 \mathrm{~min}$.

X-ray photoelectron spectroscopy (XPS) data were recorded with a triple channeltron CLAM2 analyzer and $\mathrm{Mg} \mathrm{K \alpha}$ radiation from the samples whose description is given in Table 1 . The widescan spectra were recorded using a constant pass energy of $100 \mathrm{eV}$, whereas the narrow-scan spectra were recorded at a constant pass energy of $20 \mathrm{eV}$. All the spectra were recorded at take-off angles of $90^{\circ}$. The base pressure in the analysis chamber was typically around $6 \times 10^{-9} \operatorname{mbar}\left(6 \times 10^{-7} \mathrm{~Pa}\right)$.

A KRUSS DAS 100 instrument was used for contact angle measurements. This computer-controlled contact angle analyzer allowed us to measure static and dynamic contact angle along with surface tension and surface energy. The position of the sample stage can be precisely adjusted along the $x_{-}, y_{-}$, or $z$-axis. An optical system using variable intensity illumination controls the degree of backlighting. The optics can be tilted by up to $3^{\circ}$ allowing us to choose the angle of view required for rough or uneven surfaces. The instrument contains a stepping motor-controlled syringe system for precise and repeatable liquid drop formation and application. This insures that a reproducible drop volume is applied to the surface. The micro-syringe attachment facilitates rapid and precise formation of water drop specimens. Following placement of a sessile drop, the syringe is easily swung from the field of view. It will return to its exact working location for placement of the

Table 1

Sample description

\begin{tabular}{lccl}
\hline Sample & He flow $(\mathrm{sccm})$ & $\mathrm{N}_{2}$ flow $(\mathrm{sccm})$ & Dominant species \\
\hline A & - & - & - \\
B & 100 & 50 & $\mathrm{~N}_{2}, \mathrm{NO}$ \\
C & 100 & 20 & $\mathrm{~N}_{2}, \mathrm{~N}_{2}^{+}, \mathrm{NO}$ \\
D & 100 & 0 & $\mathrm{~N}_{2}^{+}, \mathrm{HeI}, \mathrm{OI}, \mathrm{OH}$ \\
\hline
\end{tabular}


subsequent drop. Alternatively, it can remain at the working location, allowing continuously adding or withdrawing fluid from a sessile drop for the purpose of forming advancing or receding contact angles. After placing the water droplet, the contact angle was measured using the circular curve fit option of the software.

Cell survival and proliferation were determined using mouse MC3T3 osteoblastic cells that were seeded on coated glass cover slips at an initial density of $5 \times 10^{4}$ cells per disc. The MTT assay was used to quantify the number of viable cells after 3 days of culture. This test is a quantitative colorimetric method to determine cell proliferation. It utilizes the yellow tetrazolium salt (MTT), which is metabolized by mitochondrial succinic dehydrogenase activity of proliferating cells to yield a purple formazan reaction product. Data from DLC-coated and plasma-treated samples were normalized to those from specimens not plasmatreated.

\section{Results and discussion}

\subsection{Characteristics of the open-air $\mathrm{He} / \mathrm{N}_{2}$ dielectric barrier discharges}

The current waveforms for the open-air atmospheric plasma discharges employed to treat DLC samples are shown in Fig. 2. The overall shape of the waveforms for the three plasma treatments is controlled by the width and repetition rate of the high-voltage pulses produced by the power supply, however, the noise of the current waveform decreased monotonically with $\mathrm{N}_{2}$ gas flow. This indicates a higher degree of homogeneity for glow discharges of $\mathrm{He} / \mathrm{air}$ in comparison to that of $\mathrm{He} / \mathrm{N}_{2}$. Visual observations of the atmospheric pressure plasma indicated that the three DBD processes were stable.

Optical emission spectroscopy was applied to identify the chemical species formed in the discharge. Fig. 3 compares the emission spectra for the various gas mixtures. Because the
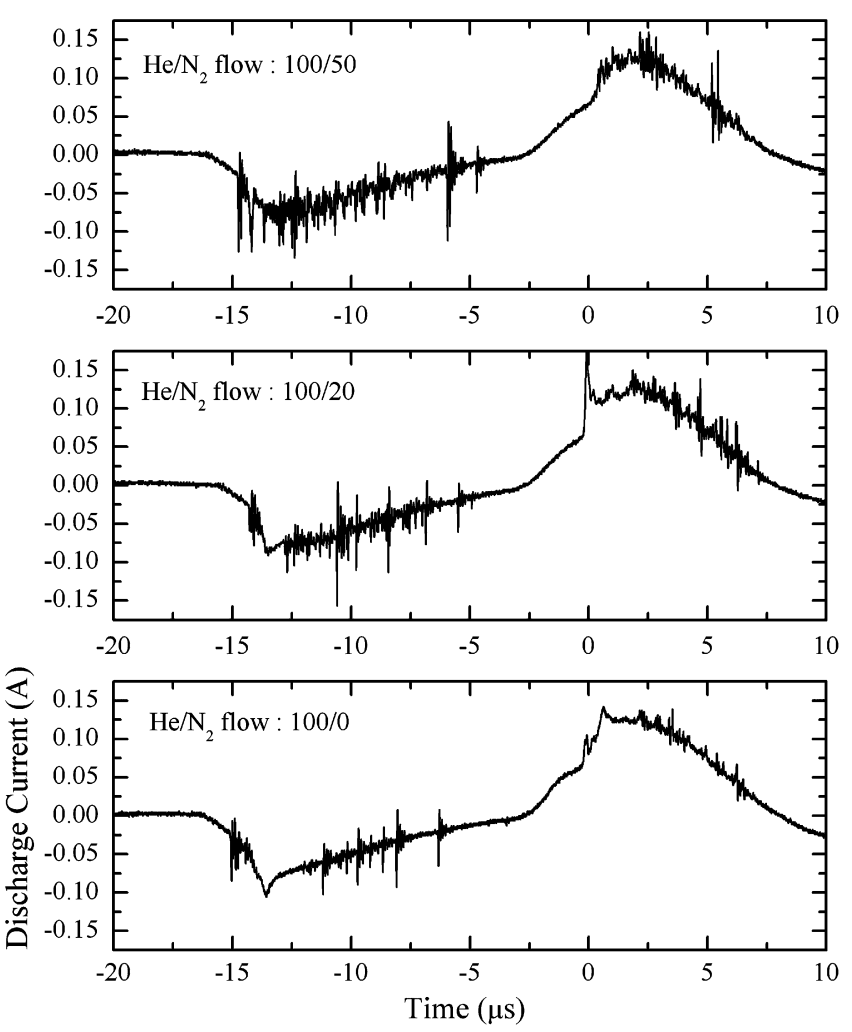

Fig. 2. Current waveforms of open-air atmospheric plasma discharge.
Table 2

Description of possible reactions in $\mathrm{He} / \mathrm{N}_{2}$ dielectric barrier discharge (DBD) plasma

$\mathrm{He}+\mathrm{e}_{>22.72 \mathrm{ev}}^{-} \rightarrow \mathrm{He}^{*}+\mathrm{e}_{\text {slow }}^{-}$

$\mathrm{He}^{\mathrm{M}}+\mathrm{e}_{>2.92 \mathrm{eV}}^{-} \rightarrow \mathrm{He}^{*}+\mathrm{e}_{\text {slow }}^{-}$

$\mathrm{N}_{2}+\mathrm{e}_{>11.05 \mathrm{eV}}^{-} \rightarrow\left(\mathrm{N}_{2}\right)^{*}+\mathrm{e}_{\text {slow }}^{-}$

$\mathrm{N}^{2+}+\mathrm{e}^{-}+\mathrm{X} \rightarrow\left(\mathrm{N}_{2}\right)^{*}+\mathrm{X}$

$\mathrm{He}^{\mathrm{M}}+\mathrm{N}_{2} \stackrel{\text { Penning ionization }}{\longrightarrow} \mathrm{N}^{2+}+\mathrm{e}^{-}+\mathrm{He}$

$\mathrm{N}^{2+}+\mathrm{e}_{\text {fast }}^{-} \rightarrow\left(\mathrm{N}_{2}^{+}\right)^{*}+\mathrm{e}_{\text {slow }}^{-}$

$\mathrm{He}^{*}$ is excited atom of $\mathrm{He}$ which cause of $\mathrm{He}$ I radiation; $\mathrm{He}^{\mathrm{M}}$ is meta-stable $\left(2^{3} \mathrm{~S}\right)$ atom of $\mathrm{He} ;\left(\mathrm{N}_{2}\right)^{*}$ is excited of nitrogen molecule which cause of $\mathrm{N}_{2}$ species; $\left(\mathrm{N}_{2}^{+}\right)^{*}$ is excited of nitrogen molecule ion which cause of $\mathrm{N}_{2}^{+}$species.

atmospheric plasma treatments were carried out in open air, the decrease in $\mathrm{N}_{2}$ flow from 50 to $0 \mathrm{sccm}$ implies that the $\mathrm{N}_{2}$ flow is replaced by laboratory air. The list of the possible reactions happening between $\mathrm{N}_{2}$ and $\mathrm{He}$ is shown in Table 2. In samples $\mathrm{B}\left(\mathrm{N}_{2}\right.$ flow $=50 \mathrm{sccm})$ and $\mathrm{C}\left(\mathrm{N}_{2}\right.$ flow $\left.=20 \mathrm{sccm}\right)$, transfer of energy from the helium $19.8 \mathrm{eV}$ metastable energy level induces dissociation of the $\mathrm{N}_{2}$ molecule, which produces the formation of NO, as can be observed in Fig. 3. The presence of $\mathrm{OH}$ band in the emission spectra for sample D (100 sccm He, $0 \mathrm{sccm} \mathrm{N}_{2}$ ) reveals the presence of water in the plasma because the gas flow is reduced for this sample. In this case, OI and HeI emission is observed which can come from a direct electron excitation, while nitrogen $\mathrm{N}_{2}{ }^{+}$and $\mathrm{OH}$ are likely due to Penning ionization via the metastable $\mathrm{He}^{*}[22]$.

\subsection{X-ray photoelectron spectroscopy}

The wide-scan spectra recorded from the different samples are presented in Fig. 4. As expected, intense $C$ 1s peaks dominate the spectra. All the spectra show noticeable oxygen contributions. Besides that, all the plasma-treated samples showed nitrogen contributions, which are an indication that nitrogen has been incorporated into the DLC films, even in the sample that has been treated in a flow of He and air (sample D). Table 3 collects the relative atomic concentrations obtained from the XPS data. It is interesting to note that the sample treated with the highest $\mathrm{N}_{2}$ flow (50 sccm) presents the highest nitrogen content among all treated samples, while the other two have lower, comparable nitrogen contents.

Fig. 5 shows the narrow-scan $C$ 1s spectra recorded from all the samples. The spectra have been fitted considering four different

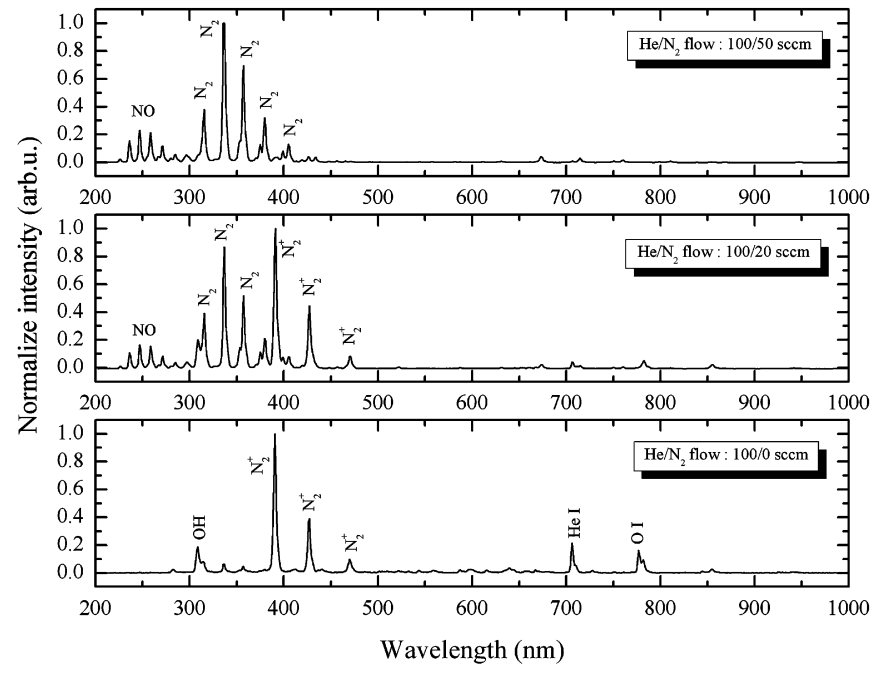

Fig. 3. Emission spectra of open-air atmospheric plasma discharge. 


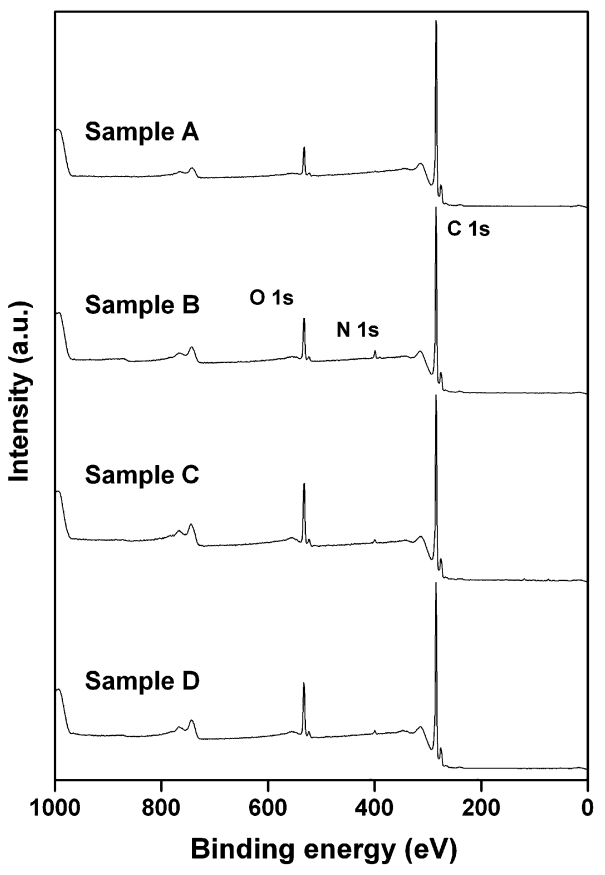

Fig. 4. Wide-scan XPS spectra recorded from the surface of the "as-deposited" DLC (sample A) and $\mathrm{He}+\mathrm{N}_{2}$ DBD-treated DLC films (samples B-D).

carbon peaks. The results of the fit are presented in Table 4 . In the case of the DLC film, the peak appearing at $284.6 \mathrm{eV}$ corresponds to the $\mathrm{sp}^{2}$ contribution characteristic of DLC $[23,24]$, while that at $285.5 \mathrm{eV}$ corresponds to the $\mathrm{sp}^{3}$ contribution [23,24]. In the present case, the peak at $287.1 \mathrm{eV}$ does not necessarily correspond to a different chemical species rather, more likely, it accounts for the high-binding energy side asymmetry, which is known to exist in the $\mathrm{sp}^{2}$ contribution $[23,24]$. Finally, the peak at $288.6 \mathrm{eV}$ corresponds to the presence of $\mathrm{C}-\mathrm{O}$ bonds. As shown in Table 4, the

Table 3

Relative atomic concentrations calculated from the XPS data

\begin{tabular}{llll}
\hline Sample & Carbon (at\%) & Oxygen (at\%) & Nitrogen (at\%) \\
\hline A & 94 & 6 & - \\
B & 88 & 9.5 & 2.5 \\
C & 86 & 13 & 1 \\
D & 87 & 12 & 1 \\
\hline
\end{tabular}

Table 4

XPS binding energies and relative spectral areas of the different contributions present in the $C 1$ s spectra

\begin{tabular}{lcccc}
\hline Sample & C1 & C2 & C3 & C4 \\
\hline A & & & & \\
BE (eV) & 284.6 & 285.5 & 287.1 & 288.6 \\
Area (\%) & 68 & 25 & 5 & 2 \\
B & & & & \\
BE (eV) & 284.6 & 285.6 & 287.1 & 288.6 \\
Area (\%) & 77 & 15 & 5 & 3 \\
C & & & & 288.8 \\
BE (eV) & 284.6 & 285.6 & 287.1 & 4 \\
Area (\%) & 74 & 13 & 6 & 3 \\
D & & & & 287.0 \\
BE (eV) & 284.6 & 285.6 & 6 & 28.6 \\
Area (\%) & 74 & 16 & & \\
\hline
\end{tabular}

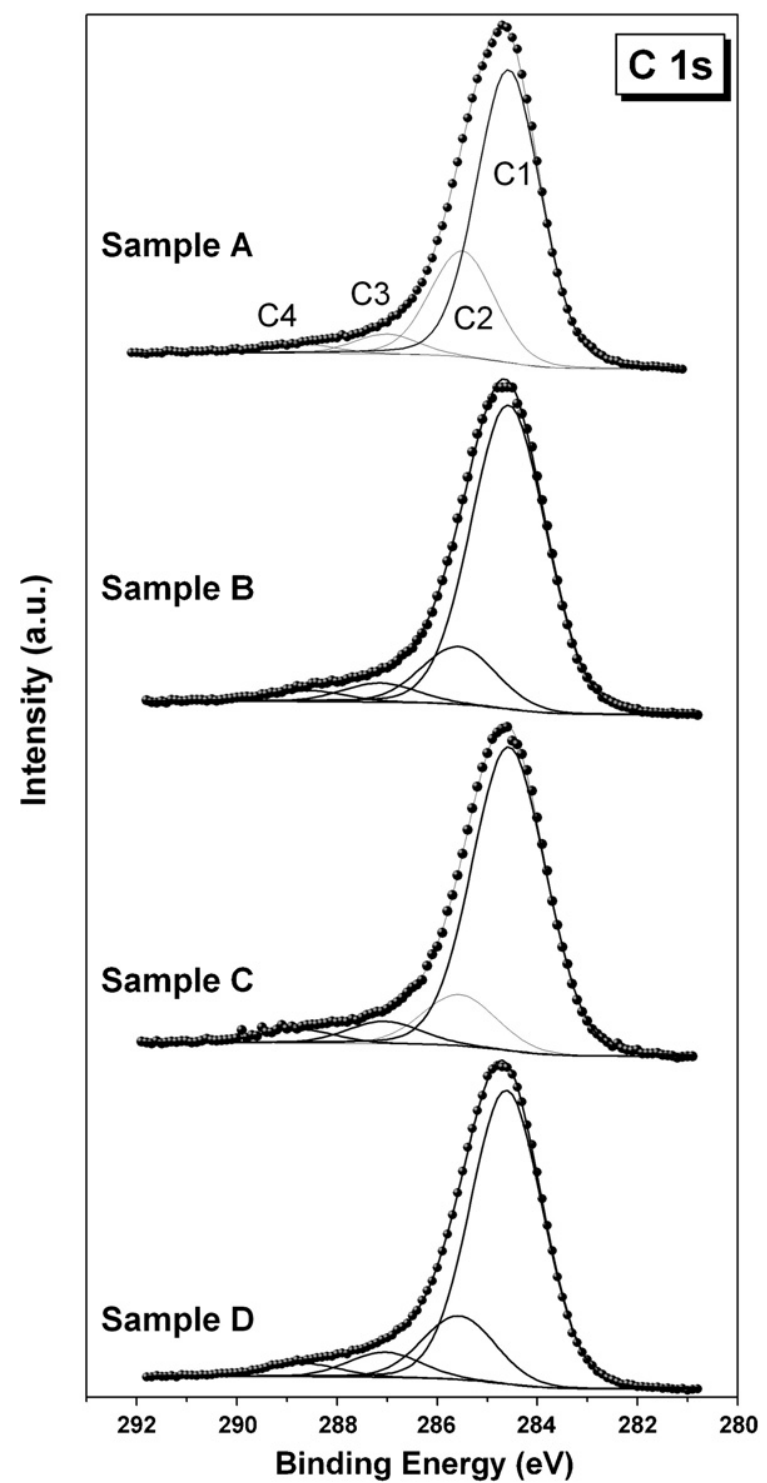

Fig. 5. C 1s spectra recorded from the surface of the "as-deposited" DLC (sample A) and $\mathrm{He}+\mathrm{N}_{2}$ DBD-treated DLC films (samples B-D).

contribution of the peak appearing at $284.6 \mathrm{eV}$ increases slightly due to the application of DBD surface treatments.

Since the wide-scan spectra have shown that nitrogen was incorporated into the DLC films, the contributions at 284.6, 285.5, 287.1 and $288.6 \mathrm{eV}$ present in the spectra of the treated samples can also be associated with the presence of $\mathrm{C}-\mathrm{C}, \mathrm{C}=\mathrm{N}, \mathrm{C}-\mathrm{N}$ or $\mathrm{C} \equiv \mathrm{N}$ and $\mathrm{C}-\mathrm{O}$ bonds, respectively [24]. We must take into account, however, that the amount of $\mathrm{N}$ present in the samples is very small (1-2.5\%), therefore, these contributions must represent only a small fraction of the total peak area. In general, all the spectra recorded from the treated samples were very similar.

The N 1s spectra recorded from the treated samples are shown in Fig. 6. All of them show three contributions (see also Table 5). The one appearing at $398.8 \mathrm{eV}$ can be associated with the presence of $\mathrm{C}-\mathrm{N}$ or $\mathrm{C} \equiv \mathrm{N}$ bonds, the main one at $399.9 \mathrm{eV}$ can be assigned to $\mathrm{C}=\mathrm{N}$ bonds and, finally, the contribution at $401.7 \mathrm{eV}$ might arise either from the existence of $\mathrm{N}-\mathrm{O}$ bonds $[25,26]$ and/or quaternary nitrogen ( $\mathrm{N}$ bonded to three $\mathrm{C}$ atoms within a graphitic domain) [27-29]. The intensity of this latter contribution is noticeably higher in the spectrum recorded from the sample treated in $\mathrm{He}$ and air (sample D) than in the other two samples (Table 5). 


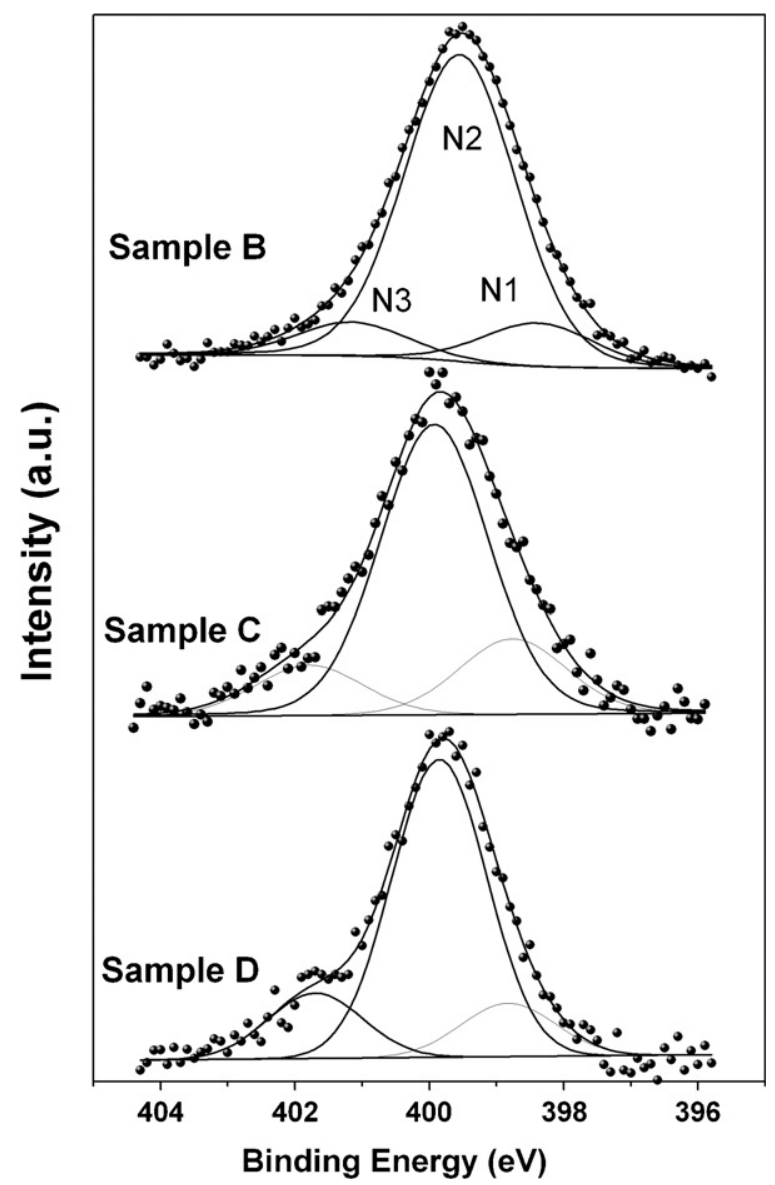

Fig. 6. $\mathrm{N} 1 \mathrm{~s}$ spectra recorded from the surface of $\mathrm{He}+\mathrm{N}_{2}$ DBD-treated DLC films (samples B-D).

Finally, we note that all the 0 1s spectra recorded from all the samples were very similar and were composed by a quite symmetric peak centered at $532.6 \mathrm{eV}$.

\subsection{Contact angle measurements}

The evolution of the contact angle for the different DBD plasma treatments for an aging time up to 300 days is shown in Fig. 7. The first observation concerns the uniformity of the untreated DLC film (sample A), which had a contact angle $\sim 75^{\circ}$ for the entire sampled ageing time. The sample treated with the highest $\mathrm{N}_{2}$ flow (sample $\mathrm{B}, \mathrm{N}_{2}=50 \mathrm{sccm}$ ) evolved from an initial hydrophilic behavior (contact angle $=53 \pm 4^{\circ}$ ) to a hydrophilic/hydrophobic behavior

Table 5

XPS binding energies and relative spectral areas of the different contributions present in the $\mathrm{N} 1 \mathrm{~s}$ spectra

\begin{tabular}{lccc}
\hline Sample & N1 & N2 & N3 \\
\hline B $\mathrm{BE}(\mathrm{eV})$ & 398.4 & 399.5 & 401.7 \\
Area (\%) & 11 & 80 & 9 \\
C & & & \\
BE $(\mathrm{eV})$ & 398.8 & 399.9 & 401.7 \\
Area (\%) & 18 & 70 & 12 \\
D & & & \\
BE (eV) & 398.8 & 399.9 & 401.7 \\
Area (\%) & 13 & 71 & 16 \\
\hline
\end{tabular}

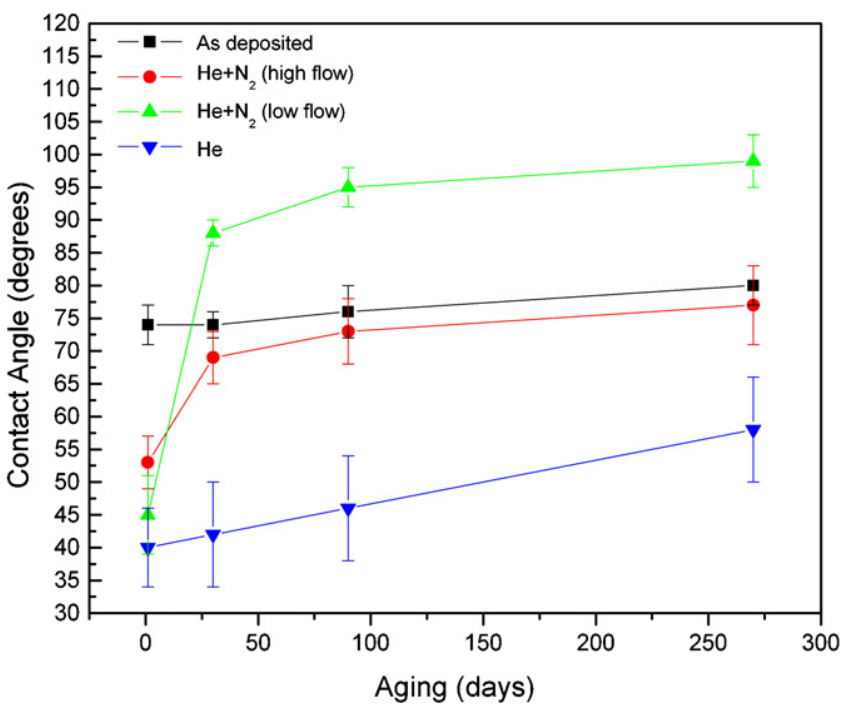

Fig. 7. Evolution of wettability of untreated (sample A) and $\mathrm{He}+\mathrm{N}_{2}$ DBD-treated DLC films (samples B-D).

similar to the one observed for the untreated DLC sample. The fast degree of recovery for this sample suggests that the presence of molecular $\mathrm{N}_{2}$ species in the DBD plasma does not produce any longterm change in surface energy of the DLC surface, although it can increase the atomic percentage of nitrogen in the surface of the DLC.

In the case of the sample treated with the lower $\mathrm{N}_{2}$ flow (sample $\mathrm{C}, \mathrm{N}_{2}=20 \mathrm{sccm}$ ), the behavior is hydrophilic immediately after plasma treatment, however, after 30 days of aging, this behavior changed to hydrophobic (contact angle $=88 \pm 3^{\circ}$ ), and its hydrophobic behavior increases further over time. The contact angle after 270 days of aging time increased to $99 \pm 4^{\circ}$. The hydrophobic behavior is probably a consequence of the higher presence of $\mathrm{C}-\mathrm{N}$ or $\mathrm{C} \equiv \mathrm{N}$ bonds as it was reported in the previous section, and as shown in Fig. 6 and Table 5. The cause for the observed decrease in surface energy could also be related to the strong presence in the discharge of ionized $\mathrm{N}_{2}{ }^{+}$(instead of neutral gas molecules $\mathrm{N}_{2}$ ), as it was observed in Fig. 3. Finally, in the case of the sample treated with He and air (sample $\mathrm{D}, \mathrm{N}_{2}=0 \mathrm{sccm}$ ), the evolution of the contact angle indicates that the sample behaves and remains hydrophilic even after 270 days

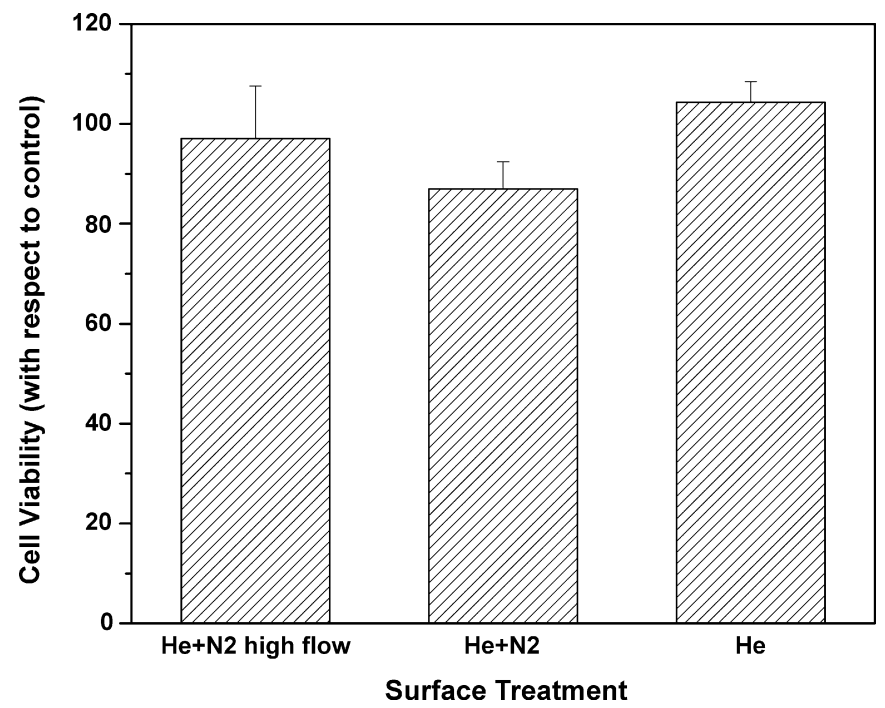

Fig. 8. Effects of $\mathrm{He}+\mathrm{N}_{2}$ DBD surface treatment on cell viability in vitro of DLC. Data from coated substrates were normalized to those from the untreated DLC sample. 
of the applied DBD treatment. In this case, the presence of air in the DBD plasma can affect the bonding of nitrogen to the surface. In the previous section, it was shown that this sample contained the highest contribution of $\mathrm{N}-\mathrm{O}$ bonds and/or quaternized nitrogen moieties, in comparison to the other two surface treatments. The observed behavior is therefore expected since the presence of more $\mathrm{N}-\mathrm{O}$ bonds and/or the presence of an ionic species as the quaternized nitrogen on the surface of the surface of the DLC sample would result in a strong polarity.

\subsection{Cell viability}

The results for cell proliferation after 3 days of culture for all the treated samples (with respect to untreated specimens) are shown in Fig. 8. Statistical analyzes on the cell culture data were performed by means of a paired $t$-test. Overall, it can be observed that the percentage of attached cells for all surface treatments is near 100\% that of the untreated hydrogen-free DLC film, which is an indicator of a high biocompatibility. In a very recent study, we have reported that the cell viability of nonhydrogenated DLC is significantly superior to that of hydrogenated DLCs [30]. In this study, our analyzes show that after three tests there were no statistically significant differences in the number of viable cells between sample D (DBD plasma treatment with $\mathrm{He}+$ air) and the sample $\mathrm{B}$ (treated with high- $\mathrm{N}_{2}$ flow). However, the number of viable cells in sample $D$ was higher $(p<0.05)$ than that of sample $C$ (treated with low- $\mathrm{N}_{2}$ flow). These results indicate that cellular attachment and growth in DBD-treated DLC samples is favored by a hydrophilic surface. They also underscore the potential of open-air DBD plasma treatments in the modification of DLC-coated surface for enhanced biomedical compatibility.

\section{Summary and conclusions}

A dielectric barrier discharge technique has been employed to functionalize the surface of DLC films. DBD plasmas using mixtures of helium and nitrogen have been shown to modify the surface chemistry and wettability of hydrogen-free DLC films.

This study revealed that DBD plasma discharges can be used to incorporate small amounts of nitrogen on the surface of the DLCs and, given the capacity of nitrogen to carry positive charge, its presence (even in small amounts) can have a marked effect on the interactions between the DLC surface and some biological systems. The influence of homogeneous nitrogen-helium DBD plasma treatments was compared to those of air-helium DBDs on hydrogen-free DLC regarding the long-term wettability and MC3$\mathrm{T} 3$ cell viability. XPS analysis revealed an increase in $\mathrm{N}-\mathrm{O}$ bonds in comparison with the application of air-helium DBD plasmas; most likely causing the observed increase in hydrophilicity and cell attachment of mouse osteoblast MC3-T3 cells. The evolution of the wettability indicated that the change in surface energy caused by nitrogen-helium DBD plasma was capable of lasting after a prolonged aging period of 300 days.

This study suggests that open-air DBD plasma technologies could be applied to DLC surfaces in order to modify and control the attachment of biomolecules such as proteins, enzymes and DNA.
Further work will examine the influence of these DBD plasmatreated DLCs on the differentiation of DNA molecules.

\section{Acknowledgments}

Helpful discussions with Prof. S. Santucci (CASTI) are gratefully acknowledged. Authors are also grateful to P. De Marco for her help in measuring the contact angle of water. Financial support from the Marie Curie Outgoing Fellowship Grant MOIF-CT-2005-02195 is gratefully acknowledged. Work at Lawrence Berkeley National Laboratory was supported by the U.S. Department of Energy under Contract No. DE-AC02-05CH11231. Financial support from the Spanish Ministry of Education under project MAT2004-01451 is also gratefully acknowledged.

\section{References}

[1] Y. Kaibara, K. Sugata, M. Tachiki, H. Umezawa, H. Kawarada, Diamond Relat Mater. 12 (2003) 560.

[2] M. Allen, F. Law, N. Rushton, Clin. Mater. 17 (1994) 1.

[3] R. Butter, M. Allen, L. Chandra, A.H. Lettington, N. Rushton, Diamond Relat. Mater. 4 (1995) 857.

[4] L. Chandra, M. Allen, R. Butter, N. Rushton, I.M. Hutchings, T.W. Clyne, Diamond Relat. Mater. 5 (1996) 410.

[5] S.E. Rodil, C. Ramirez, R. Olivares, H. Arzate, J. Reyes-Gasga, C. Magana, Diamond Relat. Mater. 15 (2006) 1300.

[6] M. Grischke, A. Hieke, F. Morgenweck, H. Dimigen, Diamond Relat. Mater. 7 (1998) 454.

[7] R. Hauert, Diamond Relat. Mater. 12 (2003) 583.

[8] D.-Y. Wang, Y.-Y. Chang, C.-L. Chang, Y.-W. Huang, Surf. Coat. Technol. 200 (2005) 2175.

[9] S.C.H. Kwok, J. Wang, P.K. Chu, Diamond Relat. Mater. 14 (2005) 78.

[10] O. Goossens, E. Dekempeneer, D. Vangeneugden, R. Van de Leest, C. Leys, Surf. Coat. Technol. 142-144 (2001) 474.

[11] G. Borcia, A. Chiper, I. Rusu, Plasma Sources Sci. Technol. (2006) 849.

[12] S.F. Mirala, E. Monette, R. Bartnikas, G. Czeremuszkin, M. Latreche, M.R. Wertheimer, Plasmas Polym. 5 (2000) 63.

[13] R. Seebock, H. Esrom, M. Charbonnier, M. Romand, U. Kogelschatz, Surf. Coat. Technol. 142-144 (2001) 455.

[14] H.F. Hildebrand, N. Blanchemain, G. Mayer, F. Chai, M. Lefebvre, F. Boschin, Surf. Coat. Technol. 200 (2006) 6318.

[15] S. Kanazawa, M. Kogoma, T. Moriwaki, S. Okazaki, J. Phys. D: Appl. Phys. (1988) 838.

[16] N. Gherardi, G. Gouda, E. Gat, A. Ricard, F. Massines, Plasma Sources Sci. Technol. 9 (2000) 340.

[17] U. Kogelschatz, Plasma Chem. Plasma Process. 23 (2004) 1.

[18] A. Anders, I.G. Brown, R.A. MacGill, M.R. Dickinson, J. Phys. D: Appl. Phys. 31 (1998) 584.

[19] A. Anders, N. Pasaja, S. Sansongsiri, Rev. Sci. Instrum. 78 (2007) 63901.

[20] J. Robertson, Mater. Sci. Eng.: R 37 (2002) 129.

[21] R.A. MacGill, M.R. Dickinson, I.G. Brown, Vacuum arc ion sources-micro to macro, in: Proceedings of the Sixth International Conference on Ion Sources, Whistler, Canada, (1996), pp. 1210-1212.

[22] F. Massines, P. Segur, N. Gherardi, C. Khamphan, A. Ricard, Surf. Coat. Technol. 174-175 (2003) 8.

[23] J. Diaz, G. Paolicelli, S. Ferrer, F. Comin, Phys. Rev. B: Condens. Matter 54 (1996) 8064.

[24] E. Riedo, F. Comin, J. Chevrier, F. Schmithusen, S. Decossas, M. Sancrotti, Surf. Coat. Technol. 125 (2000) 124

[25] T.W. Scharf, R.D. Ott, D. Yang, J.A. Barnard, J. Appl. Phys. 85 (1999) 3142.

[26] Z. Zhou, L. Xia, M. Sun, Diamond Relat. Mater. 13 (2004) 14.

[27] K.A. Grant, Q. Zhu, K.M. Thomas, Carbon 32 (1994) 883.

[28] Q. Zhu, S.L. Money, A.E. Russell, K.M. Thomas, Langmuir 13 (1997).

[29] J.C. Sánchez-Löpez, C. Donnet, F. Lefèvre, C. Fernández-Ramos, A. Fernández, J. Appl. Phys. 90 (2001) 675.

[30] J.L. Endrino, A. Matthew, R. Escobar Galindo, H. Zhang, A. Anders, J.M. Albella, Mater. Res. Soc. Symp. Proc. 950 (2006). 